\title{
Contribuições da formação de professores em cursos de graduação para o uso das TICs nas escolas
}

\author{
Elizabeth Sarates Carvalho Trindade, SMED - PMPA \\ elizabethsctrindade@gmail.com
}

\begin{abstract}
RESUMO: Esta pesquisa qualitativa analisou o processo de apropriação tecnológica de professoras do ensino fundamental da Rede Municipal de Ensino de Porto Alegre (RME/PoA) que também eram alunas de um Curso de Graduação em PedagogiaLicenciatura, na modalidade a distância, da Universidade Federal do Rio Grande do Sul (PEAD/UFRGS), e a contribuição desse processo para o uso das Tecnologias de Informação e Comunicação (TICs) em práticas nas escolas. A coleta de dados foi realizada mediante levantamentos de registros, depoimentos e reflexões nos ambientes virtuais do Curso, entrevistas e observações de atividades em laboratórios de informática nas escolas. Organizados em duas categorias de análise: Apropriação Tecnológica e Uso das tecnologias em práticas nas escolas. A análise dos dados baseouse nos conceitos de construção do conhecimento de Jean Piaget e nos níveis de explicitações do modelo de redescrição representacional de Kamirloff-Smith (1995). Os resultados mostram que as experiências das professoras-alunas no curso, baseado no uso intensivo de TICs, proporciona condições para que se estabeleça um processo de apropriação tecnológica que repercute em diferentes formas de usos das tecnologias disponíveis nas escolas, bem como em mudanças graduais nas práticas escolares.
\end{abstract}

PALAVRAS-CHAVE: práticas escolares, tecnologias da informação e comunicação, apropriação tecnológica e formação de professores.

\section{Contributions from teachers' education in graduation courses for the use of ICTs in schools}

\begin{abstract}
This qualitative research analyzed the process of technological appropriation by female elementary school teachers from the Porto Alegre municipal public school system (RME/PoA), who were also students on the Pedagogy Course, in the distance learning modality, at the Universidade Federal do Rio Grande do Sul (PEAD/UFRGS), as well as the contribution from this process to the use of Information and Communication Technologies (ICTs) in their practices in schools. Data were collected through surveys of records, testimonies and reflections in virtual environments of the course, interviews, activities, and classroom observations in the schools' computer laboratories. They were organized into two analytical categories: technological appropriation and use of the technologies in practices in schools. The data analysis was based on the concepts of knowledge building by Jean Piaget and on the levels of explicitation from the Karmiloff-Smith's Representational redescription model (1995). Results showed that the teachers-students' experiences in the course, based on the intensive use of ICTs, provide the necessary conditions to establish a process of technological appropriation that impacts on different ways of the use of technologies in schools, as well as on gradual changes in scholar practices.
\end{abstract}

KEYWORDS: school practices, Information and Communication Technologies, technological appropriation and formation of teachers. 


\section{Introdução}

O uso das TICs pela sociedade impõe mudanças constantes aos nossos comportamentos. Como afirma Pretto (2006, p. 14-17), há mudanças na economia, no mercado financeiro, na política e também na organização escolar. Desse modo, são crescentes as políticas públicas protagonizadas por ações do Ministério da Educação e Cultura (MEC) na tentativa de fomentar o uso das TICs como recurso para elevar a qualidade do ensino das escolas da rede pública brasileira.

Há distribuição de equipamentos tecnológicos, computadores e aparelhos, como, por exemplo, o ProInfo Integrado, assim como conteúdos e recursos multimídia/digitais por meio do Portal do Professor, pela TV Escola e DVD Escola, pelo Domínio Público e pelo Banco Internacional de Objetos Educacionais (ProInfo Integrado, 2010). Há também legislações indicando diretrizes curriculares nacionais para a formação de professores da educação básica com o uso de TICs, incluindo metodologias, estratégias e materiais de apoio inovadores a fim de fomentar a "simetria invertida", ou seja, considerar que o professor deva ser preparado da mesma forma como dele se espera que atue quando estiver na função de professor (Brasil, 2002).

Diante desse cenário, foi realizada uma pesquisa com o objetivo de investigar a repercussão do processo de apropriação tecnológica vivido por professoras da Rede Municipal de Ensino de Porto Alegre (RME/PoA), no Curso de Graduação-Licenciatura da Universidade Federal do Rio Grande do Sul na modalidade a Distância (PEAD/UFRGS), para o uso de TICs em práticas nas escolas. Trata-se de um estudo de caso, no qual a coleta de dados utilizou múltiplas fontes de materiais disponíveis: leituras de materiais produzidos e postados em ambientes internos da UFRGS, observações de práticas de conduções de aulas em laboratórios de informática e entrevistas.

Este estudo pretende contribuir para a compreensão de como o processo de apropriação tecnológica repercute em diferentes tipos de uso das TICs nas escolas. Demonstra-se, assim, a necessidade de um investimento de formação de longa duração, com momentos de experimentações e de reflexão das práticas, a fim de que se consiga introduzir inovações pedagógicas pertinentes e contínuas para além dos cursos de formação de professores.

\section{Contextualização teórica}

A partir da compreensão inicial do funcionamento da inteligência humana e do processo de construção do conhecimento dos estudos de Jean Piaget, pareceu-nos possível entender o processo de apropriação tecnológica e a possível aplicação desses conhecimentos em uma transposição didática que impulsione o professor ao uso de TICs em práticas nas escolas. Levamos em consideração o que é descrito por Jean Piaget sobre a construção do conhecimento e, consequentemente, sobre a inteligência, que está ligada à ação do sujeito sobre o objeto ou sobre os acontecimentos do meio: na interação, o sujeito age sobre o objeto e sofre a ação do objeto de maneira a construir seu próprio conhecimento e sua própria capacidade de conhecer (Piaget, 1973, p. 15).

Para conhecer, é preciso que o indivíduo aja sobre o real, a fim de "compreendêlo, em função dos sistemas de transformações aos quais estão ligadas as ações”. Uma ação compreendida como um processo de "coordenar esquemas entre si ou encaixá-los num sistema regido por leis de totalidade”. Para entendermos os mecanismos mentais 
envolvidos na ação, nos atos inteligentes do indivíduo, é preciso compreender o funcionamento de dois processos fundamentais da atividade inteligente: "assimilação e acomodação” (Dolle, 1975, p. 58), pois explicam a constituição dos componentes de um todo no equilíbrio cognitivo. Dois polos inseparáveis, duas orientações solidárias entre si, que, juntas, uma com a outra, compõem o todo indissociável (Piaget, 1976, p. 13-43).

As ações do sujeito não acontecem ao acaso. Tendem a ser aplicadas ou utilizadas e até mesmo repetidas de maneira semelhante em situações comparáveis, pois o sujeito tende a reproduzir suas ações, se persistirem os mesmos interesses, correspondendo a situações análogas. Do mesmo modo, se as necessidades e as situações se codificarem, o sujeito pode ser capaz de diferenciar ou combinar essas ações de uma nova maneira, modificando e formando, assim, esquemas de ações (Piaget, 1973, p. 16). São processos disparados, segundo Piaget, por um desequilíbrio gerado por um estímulo externo, que levaria o sujeito a buscar um novo equilíbrio, tendo como base as assimilações e acomodações antigas e aquelas geradas em função da nova situação. Um processo interno do sujeito, que só pode ser percebido a partir de suas novas ações e representações.

Em continuidade a esses estudos, Karmiloff-Smith (1995) compõe as teorias cognitivas conforme Piaget e apresenta um modelo denominado de redescrição representacional (RR). Nele são visíveis os processos vividos pelos sujeitos em busca de respostas possíveis. Evidências mostram o sistema representacional humano, complexo, envolvendo algo para além dos processos de assimilação e acomodação, a partir do princípio de que entre uma informação implícita, representada de forma procedural na mente do sujeito, e uma informação explícita, verbalmente apresentada por ele, existem níveis de representação hierarquicamente organizados. É proposta a ideia de que, quanto maior consciência a respeito do conhecimento adquirido, maior será a flexibilidade cognitiva conseguida, uma vez que a apropriação do conhecimento é entendida como base no processo reinterativo de redescrição das representações obtidas por meio de relações entre diferentes domínios (Karmiloff-Smith, 1995, p. 26).

Portanto, a interação do sujeito com os estímulos externos, para Karmiloff-Smith (1992), como o meio pelo qual o homem se apropria do conhecimento e é capaz de resolver seus problemas, forneceu dados para que a autora propusesse o modelo de redescrição representacional. Trata-se de um processo em que a informação implícita na mente do sujeito passa a um conhecimento explícito, subsequente (Karmiloff-Smith, 1995, p. 18), sendo que o armazenamento do conhecimento ocorre primeiramente dentro de um domínio específico, para, mais tarde, estabelecer relações com outras representações dentro de um mesmo domínio ou até entre domínios diferentes.

A característica de inter-relação entre os domínios permitiria a representação de conhecimentos sem a intervenção direta de um desequilíbrio gerado no sujeito a partir de um estímulo externo. Conforme a autora:

A mente humana não apenas trata de se apropriar do meio, iniciando-se desde o nascimento sua exploração e representação, mas também tenta se apropriar de suas próprias representações internas. Disso decorre minha defesa de um processo contínuo de redescrição representacional, que equivale a dizer que a mente humana representa recursivamente suas próprias representações internas. (Karmiloff-Smith, 1995, p. 18)

Assim como o modelo RR postula, essa representação recursiva representa fases diferentes de um mesmo processo, representa a existência de "múltiplos níveis nos quais 
um mesmo conhecimento é representado” (Karmiloff-Smith, 1995, p. 23). Fases pelas quais todo conhecimento pode passar a ser armazenado, independentemente da idade ou do desempenho cognitivo do sujeito.

O modelo RR formulado por Karmiloff-Smith supõe que a apropriação do conhecimento passa por fases nas quais o conhecimento é representado e rerepresentado sob diversas formas. As fases são denominadas como: implícito (I), explícito1 (E1), explícito 2 (E2) e explícito 3 (E3). Moraes (2000) agrega a este modelo uma visão da aprendizagem entendida como reelaboração de conhecimentos. Conforme o autor:

\begin{abstract}
em qualquer área do conhecimento, num primeiro momento da aprendizagem, o indivíduo age de forma limitada, mecânica, rotineira, por possuir em sua mente apenas conhecimentos formulados num nível implícito. Em fases posteriores, esses conhecimentos passam por um processo de explicitação, que se traduz em compreensão e domínio crescentes "das partes" e "relações entre as partes" do que ele está aprendendo. A progressiva flexibilidade cognitiva adquirida pode alcançar um nível explícito consciente (no qual o sujeito não só sabe o que faz, mas sabe os porquês) e ainda um nível explícito consciente verbal (no qual o sujeito é capaz de verbalizar estes porquês. (Moraes, 2000, p. 40)
\end{abstract}

Para Karmiloff-Smith (1995, p. 20-26), no nível implícito, as representações internas estão armazenadas na forma de procedimentos e servirão de respostas inflexíveis a estímulos do ambiente externo. Para o nível explícito 1 (que Moraes denomina de explícito), as informações procedurais são codificadas e perdem a maioria de seus detalhes, sendo as representações reduzidas a conceitos categoriais. Portanto, representações mais simples, cognitivamente mais flexíveis, possibilitam potenciais relações dentro de um mesmo domínio. Tal fato acontece porque no nível explícito as partes componentes do comportamento procedural armazenado inicialmente de forma implícita se tornam acessíveis e possibilitam relações.

Evoluindo e reelaborando, o processo irá atingir seu auge nos níveis denominados de explícito 2 (explícito consciente) e de explícito 3 (explícito consciente verbal), os quais permitem flexibilidade inter-representacional em diferentes domínios e capacidade criativa de solução de problemas. Por ser reinterativo e possibilitar relações interdomínios, os níveis explícitos não precisam de desequilíbrios externos para ocorrer, sendo desencadeados internamente.

Segundo Leme (2008), no modelo RR, “as representações implícitas não são eliminadas pela supressão, são apenas reprimidas e ativadas para uso em situações que demandam rapidez e automaticidade”. Para a autora, o que diferencia o indivíduo humano das demais espécies é a capacidade de integrar, diferenciando e organizando o conhecimento que foi construído pelas representações explícitas, ou seja, representações sobre representações. No acesso representacional, é proporcionado à espécie humana devido à sua cultura e ao fato de esta ter evoluído conjuntamente, porém independentemente, em representações acessíveis e modificáveis, por meio de reflexão e reestruturação. Essa explicitação do conhecimento, que possibilita ao indivíduo acesso ao objeto de reflexão, discussão e transformação, permite que este questione, indague e/ou passe a querer explicar seu próprio conhecimento.

Desta forma, o que foi citado sobre a construção do conhecimento de Jean Piaget e sobre o modelo proposto por Karmiloff-Smith é fundamento para a análise dos dados que descrevem como é realizada a apropriação tecnológica das professoras-alunas e o consequente uso das TICs em práticas nas escolas. 


\section{Investigação}

Este estudo teve como foco a relação entre o processo de apropriação tecnológica e a utilização de TICs em práticas nas escolas, estruturando a seguinte questão de pesquisa: como o processo de apropriação tecnológica construído durante o curso de graduação em Pedagogia Licenciatura na modalidade a distância (PEAD/UFRGS) contribuiu para que as professoras-alunas elaborassem propostas de uso das TICs em suas práticas nas escolas de ensino fundamental da Rede municipal de Ensino de Porto Alegre (RME/POA)?

São analisadas, portanto, 5 professoras que já eram docentes há algum tempo na RME/PoA, mas que não tinham formação a nível de graduação e que ficaram vinculadas ao Curso de Graduação PEAD/UFRGS, pois conseguiram ingressar por vestibular na modalidade a distância no polo de Alvorada. Sendo por tanto, 100\% das professoras com este perfil (alunas do PEAD, Polo Alvorada e trabalhadoras da RME/PoA).

O Curso de Pedagogia na modalidade a distância foi criado a partir do consórcio entre o Centro de Ciências da Educação da Universidade Federal de Santa Catarina (CCE/UFSC) e a Faculdade de Educação da Universidade Federal do Rio Grande do Sul (FACED/UFRGS), com o objetivo de graduar 400 professores com perfil específico: professores que estavam exercendo a docência nas séries iniciais do ensino fundamental de escolas públicas municipais e estaduais no Estado do Rio Grande do Sul. O Curso teve seu início em 2006, com 215 créditos, totalizando 3.225 horas, no período de 9 semestres.

A carga horária do Curso foi dividida em: 400 horas distribuídas ao longo dos 6 primeiros semestres do curso, a serem vivenciadas pelas alunas (professoras-alunas) em atividade de discussão e atividades entre colegas, mediadas por professores; 400 horas de atividade de Estágio Supervisionado, nas suas escolas, com base em um planejamento cooperativo e sob supervisão; 2.225 horas de desenvolvimento dos conteúdos específicos; 200 horas para realização do Trabalho de Conclusão de Curso (TCC). O conjunto de atividades propostas visava permitir o desenvolvimento da autonomia cooperativa, no exercício de uma prática escolar mais qualificada e condizente com os tempos atuais (Nevado, 2006). O Curso possuía 5 polos, um em cada uma das cidades: Três Cachoeiras, Alvorada, Gravataí, Sapiranga e São Leopoldo, a partir da parceria com as Secretarias Municipais de Educação.

Os espaços de atendimento aos alunos tinham infra-estrutura necessária, assegurando o uso das novas TICs. Os espaços físicos de referência, de encontro das professoras-alunas, tutores e professores do curso, para encontros on-line ou presenciais, tinham condições para atender a demanda de necessidades dos alunos de um curso a distância. Foram disponibilizados recursos humanos e tecnológicos, bem como um acervo de material educacional, útil para o desenvolvimento de ações e atividades que viessem a ser propostas no Curso. Também foram disponibilizados os equipamentos necessários para que os alunos pudessem realizar os trabalhos cooperativos, que eram

fortalecidos pela discussão acerca das diferentes práticas escolares e das reflexões teóricas que as sustentam; um espaço onde é possível o fortalecimento das relações entre colegas e professores assim como a familiaridade com o meio virtual do curso. (Nevado, 2006) 
Desse modo, os dados coletados dos materiais produzidos pelas professorasalunas submetidos à análise possibilitaram a construção de duas categorias: 1) Apropriação Tecnológica, relacionada mais a atuação como aluna do Curso PEAD/UFRGS; e 2) Uso das Tecnologias em Práticas nas Escolas, relacionada mais diretamente ao papel de professora desempenhado nas escolas de ensino fundamental. Essas categorias são descritas a seguir.

\section{Categoria Apropriação Tecnológica}

O processo da Apropriação Tecnológica que constitui essa categoria foi subdividido em 3 subcategorias, ou seja, em 3 diferentes níveis que estão apresentados nas Tabelas 1, 2 e 3. Percebemos que era possível uma caracterização individual de cada nível juntamente com a listagem de reações dos sujeitos da pesquisa perante as atividades solicitadas pelo Curso PEAD/UFRGS. A análise é fundamentada pela interpretação dos dados, considerando o modelo de redescrição representacional de Karmiloff-Smith (1995).

\section{Tabela 1 - Nível 1 da Apropriação Tecnológica das professoras-alunas: resistências iniciais ao uso das tecnologias}

\begin{tabular}{|c|l|l|l|}
\hline $\begin{array}{c}\text { Níve } \\
1\end{array}$ & \multicolumn{1}{|c|}{ Denominação } & \multicolumn{1}{|c|}{ Carracterísticas } & \multicolumn{1}{|c|}{ Análise } \\
\hline $\mathbf{1}$ & $\begin{array}{l}\text { Resistências } \\
\text { iniciais ao uso das } \\
\text { TICs - resistência } \\
\text { "natural” ao novo. }\end{array}$ & $\begin{array}{l}\text { TICs encaradas pelas professoras-alunas } \\
\text { como obstáculo e não como solução para a } \\
\text { resolução de problemas. } \\
\text { Utilização individual e particular de } \\
\text { anotações como suporte para a realização } \\
\text { das atividades utilizando TICs. }\end{array}$ & $\begin{array}{l}\text { Nível implícito do modelo de } \\
\text { redescrição representacional: } \\
\text { professoras-alunas apresentam } \\
\text { respostas para as atividades } \\
\text { propostas pelo curso. Sem } \\
\text { conseguirem explicar como } \\
\text { realizam, apenas as realizam. }\end{array}$ \\
\hline
\end{tabular}

Tabela 2 - Nível 2 da Apropriação Tecnológica das professoras-alunas: superação das resistências iniciais e estabelecimento das primeiras redes de interações

\begin{tabular}{|c|c|c|c|}
\hline Nível & Denominação & Características & Análise \\
\hline 2 & $\begin{array}{l}\text { Superação das resistências } \\
\text { iniciais e utilização das TICs } \\
\text { para o estabelecimento das } \\
\text { primeiras redes de interações. }\end{array}$ & $\begin{array}{l}\text { Participação das atividades na } \\
\text { web e busca de soluções para } \\
\text { propostas das atividades em } \\
\text { interação com colegas do } \\
\text { Curso. } \\
\text { Utilização de diferentes } \\
\text { recursos simultaneamente. }\end{array}$ & $\begin{array}{l}\text { Nível Explícito } 1 \text { do modelo de } \\
\text { redescrição representacional: } \\
\text { capacidade de explicar como } \\
\text { conseguiram resolver processos } \\
\text { direcionados ao domínio de uso } \\
\text { das TICs. }\end{array}$ \\
\hline
\end{tabular}


Tabela 3 - Nível 3 da Apropriação Tecnológica das professoras-alunas: apropriação do funcionamento, aplicações básicas das TICs e participação nas redes de interação

\begin{tabular}{|c|l|l|l|}
\hline Níve & \multicolumn{1}{|c|}{ Denominação } & \multicolumn{1}{|c|}{ Características } & \multicolumn{1}{c|}{ Análise } \\
\hline 3 & $\begin{array}{l}\text { Apropriação do } \\
\text { funcionamento e aplicações } \\
\text { das TICs a partir da } \\
\text { participação nas redes de } \\
\text { interação. }\end{array}$ & $\begin{array}{l}\text { Participação das atividades na } \\
\text { web com atitudes criativas, } \\
\text { reflexivas e produtivas. }\end{array}$ & $\begin{array}{l}\text { Nível explícito 2 e 3 do } \\
\text { modelo de redescrição } \\
\text { representacional: explicam } \\
\text { seus processos e fazem } \\
\text { hipóteses sobre os processos } \\
\text { dos outros envolvendo mais de } \\
\text { um domínio, articulam TICs e } \\
\text { conhecimento. }\end{array}$ \\
\hline
\end{tabular}

\section{Categoria Uso das Tecnologias em Práticas nas Escolas}

A categoria Uso das Tecnologias em Práticas nas Escolas foi subdividida em 3 níveis: A, B e C. Esses níveis distinguem as ações e reações das professoras-alunas em relação ao uso das TICs nas escolas, enquanto docentes atuantes no ensino fundamental, desencadeadas a partir da Apropriação Tecnológica (categoria explicitada anteriormente) vivida em função do Curso PEAD/UFRGS.

Os níveis A, B e C são caracterizados pela diferenciação gradual que as professores-alunas alcançam em relação ao uso das TICs na escola. Quanto à relação entre os níveis de Apropriação Tecnológica e ao Uso das Tecnologias em Práticas nas Escolas, salientamos que é apenas quando as professoras-alunas atingem o nível 2 da apropriação tecnológica que se tornam possíveis as primeiras experimentações das TICs nos fazeres das escolas. As Tabelas 4, 5 e 6 descrevem esses níveis apresentados pelas professoras-alunas nessa categoria.

Tabela 4 - Nível A de Uso das Tecnologias em Práticas nas Escolas: experimentações das TICs para uso nos “fazeres” docentes

\begin{tabular}{|c|l|l|l|}
\hline $\begin{array}{c}\text { Níve } \\
\text { I }\end{array}$ & \multicolumn{1}{|c|}{ Denominação } & \multicolumn{1}{|c|}{ Característica } & \multicolumn{1}{|c|}{ Análise } \\
\hline A & $\begin{array}{l}\text { Experimentações } \\
\text { das TICs em suas } \\
\text { práticas para os } \\
\text { alunos (ainda não } \\
\text { pelos alunos). }\end{array}$ & $\begin{array}{l}\text { Utilização de TICs para contribuir com suas } \\
\text { práticas. } \\
\text { Utilização de editor de texto para a } \\
\text { realização de escritos que a professora } \\
\text { necessite realizar. } \\
\text { Utilização por parte da professora de sites } \\
\text { de pesquisa para enriquecimento do } \\
\text { conteúdo desenvolvido em suas aulas. } \\
\text { Utilização de máquina fotográfica digital } \\
\text { para registro de trabalhos ocorridos na } \\
\text { escola, passeios e atividades pedagógicas } \\
\text { (como festas e eventos). }\end{array}$ & $\begin{array}{l}\text { Nede de } \\
\text { redescrição representacional: } \\
\text { passam a utilizar TICs em } \\
\text { atividades que antes estava } \\
\text { acostumada a realizar em sua } \\
\text { prática, sem TICs (pareceres, } \\
\text { diários de classe, avaliações e } \\
\text { planejamentos; aula } \\
\text { dialogada expositiva com } \\
\text { exposições de PowerPoint, } \\
\text { reuniões e apresentações com } \\
\text { a utilização de PowerPoint). }\end{array}$ \\
\hline
\end{tabular}


Tabela 5 - Nível B de Uso das Tecnologias em Práticas nas Escolas: utilização das TICs em práticas pedagógicas

\begin{tabular}{|c|l|l|l|}
\hline $\begin{array}{c}\text { Níve } \\
\text { I }\end{array}$ & \multicolumn{1}{|c|}{ Denominação } & \multicolumn{1}{|c|}{ Característica } & \multicolumn{1}{c|}{ Análise } \\
\hline B & $\begin{array}{l}\text { Utilização das TICs com os } \\
\text { alunos reproduzindo } \\
\text { atividades vivenciadas no } \\
\text { curso. }\end{array}$ & $\begin{array}{l}\text { Professoras tornam seus } \\
\text { alunos usuários do que há } \\
\text { disponível na web. } \\
\text { Professoras oferecem aos } \\
\text { alunos atividades vivenciadas } \\
\text { no curso e também outras que } \\
\text { elas são capazes de capturar } \\
\text { na Rede. }\end{array}$ & $\begin{array}{l}\text { Nível Explícito 1 do modelo } \\
\text { de redescrição } \\
\text { representacional: capacidade } \\
\text { de se colocarem no lugar de } \\
\text { seus alunos e avaliar a } \\
\text { necessidade de utilização das } \\
\text { TICs por parte de seus alunos. } \\
\text { Articulação de dois domínios. } \\
\text { Utilização de TICs e } \\
\text { necessidade de }\end{array}$ \\
& & $\begin{array}{l}\text { instrumentalização de seus } \\
\text { alunos. }\end{array}$ \\
\hline
\end{tabular}

\section{Tabela 6 - Nível C de Uso das Tecnologias em Práticas nas Escolas: uso das TICs como estratégia para promover o protagonismo dos alunos}

\begin{tabular}{|c|l|l|l|}
\hline $\begin{array}{c}\text { Níve } \\
\text { I }\end{array}$ & \multicolumn{1}{|c|}{ Denominação } & \multicolumn{1}{|c|}{ Característica } & \multicolumn{1}{|c|}{ Análise } \\
\hline C & $\begin{array}{l}\text { Uso das TICs como uma } \\
\text { estratégia para promover o } \\
\text { processo de construção de } \\
\text { conhecimento através da ação } \\
\text { e interação. }\end{array}$ & $\begin{array}{l}\text { Professoras propõem } \\
\text { atividades que promovem o } \\
\text { protagonismo dos seus alunos } \\
\text { utilizando TICs, mediante } \\
\text { projetos, escrita de textos, } \\
\text { mensagens, comunicação on- } \\
\text { line, etc. }\end{array}$ & $\begin{array}{l}\text { Nível Explícito 2 e 3 do } \\
\text { modelo de redescrição } \\
\text { representacional: capacidade } \\
\text { de articular diferentes } \\
\text { domínios para a execução de } \\
\text { suas práticas utilizando TICs } \\
\text { em busca de ferramentas que } \\
\text { promovam autoria, autonomia } \\
\text { e construção do conhecimento } \\
\text { pela ação e interação. }\end{array}$ \\
\hline
\end{tabular}

\section{Considerações Finais}

Ao final desta pesquisa podemos perceber que as professoras-alunas, que serviram como amostra para este trabalho, antes de iniciarem o Curso PEAD/UFRGS, tinham pouco ou nenhum contato com o uso de TICs e não utilizavam o computador, quer seja em sua experiência pessoal, quer seja profissionalmente. A entrada no Curso foi o obstáculo que as desafiou a se apropriarem deste novo conhecimento para, inicialmente, conseguirem cumprir com as questões exigidas pelo curso: postar as atividades como um curso a distância prevê. Aos poucos, as professoras-alunas começam a apontar indicativos que comprovam uma passagem, uma aprendizagem. Durante o processo de apropriação das TICs, as professoras-alunas ultrapassam a posição de usá-las por necessidade para realizar o curso para a posição de usá-las pelo prazer em saber utilizar 
tais recursos e em outros contextos, modificando a relação com as tecnologias que passam de obstáculos para facilitadores das ações.

Se no papel de alunas as professoras tornaram-se, gradualmente, construtoras ativas de seu próprio processo de aprendizagem, ainda enfrentaram um novo desafio: serem capazes de transpor didaticamente os conceitos aprendidos no Curso para proporcionar um aprendizado mais significativo a seus alunos, utilizando TICs. Essa possibilidade só começa a se configurar quando alcançam um nível mais avançado de apropriação dos recursos tecnológicos (nível 2), ou seja, quando há a superação das resistências ao uso das TICs devido exatamente ao domínio do conhecimento necessário a sua utilização. Quando as professoras-alunas chegam neste ponto, enquanto alunas do Curso PEAD/UFRGS, já começam a ser capazes de iniciar um processo de mudança de suas posturas pedagógicas, enquanto professoras da RME/POA. Mas o que se observa nesse momento inicial é o uso de TICs restrito ao uso pessoal do professor ou para a elaboração de material "pronto" a ser oferecido ao aluno.

A mudança dessa postura exige uma compreensão que ultrapassa o conhecimento das TICs, envolvendo o conhecimento sobre o seu uso pedagógico, sobre o processo de aprendizagem dos alunos. É importante aqui esclarecer que o simples aperfeiçoamento das condições de uso das TICs pelas alunas do Curso PEAD/UFRGS não garante que este conhecimento seja ressignificado no contexto do seu exercício enquanto docente. No entanto, o inverso não é verdadeiro: seria impossível se pensar na utilização de TICs no processo de escolarização dos alunos da RME/POA sem que seus professores tivessem o domínio desses recursos.

Por esse motivo é que se justifica a ação de algumas professoras-alunas que começam a desenvolver aulas com atividades idênticas àquelas que lhes são oferecidas no Curso PEAD/UFRGS. Embora, como alunas, sejam convidadas a protagonizarem seu processo de apropriação do conhecimento por meio da utilização dos recursos tecnológicos, em sala de aula percebem seus alunos como ainda no papel de aprendizes passivos desse processo. A contínua apropriação do uso de TICs pelas alunas do Curso as coloca no nível 3 dessa categoria, quando já são capazes de participar ativamente das redes de interação. Porém, em seu exercício profissional, embora enriqueçam suas práticas pedagógicas com atividades e recursos disponíveis na web, não conseguem se colocar como condutoras dos alunos para o papel de protagonistas na utilização das TICs.

É somente no decorrer do processo de reconstrução relativa ao uso pedagógico das TICs que os sujeitos da pesquisa conseguem efetivamente, ainda que de forma ainda tímida, realizar a transposição didática, invertendo o pressuposto da simetria invertida caracterizada pela proposta do CNE. O Curso PEAD/UFRGS, elaborado dentro desta proposta, colocou suas alunas frente a questões problematizadoras que inevitavelmente deveriam ser resolvidas com o uso das TICs. Ao promover esse ambiente de formação, de forma intencional ou não, o Curso propôs que realizassem a mesma problematização em seus ambientes de trabalho, ou seja, levassem seus alunos a enfrentar a resolução de problemas utilizando inclusive TICs.

A incidência de utilização das TICs na função docente está intimamente relacionada aos níveis propostos para essa categoria neste trabalho. Isto é, a maioria dos relatos da função docente ainda reflete atividades do nível $\mathrm{B}$, com alguns relatos de atividades que poderiam ser incluídas no nível C do uso das TICs na escola. Ora, como já comentado anteriormente, uma das explicações para esse fato é justamente a inter- 
relação, embora não diretamente proporcional, entre os níveis de apropriação das TICs pelas professoras-alunas e a capacidade de transpor esse conhecimento para a função docente. Há também a necessidade de atos criativos por parte dessas professoras-alunas ao oferecer aos seus alunos instrumentos que incitem o protagonismo destes, a fim de que produzam conhecimento e participação em suas comunidades frente aos problemas por eles enfrentados.

Com isso pode-se observar uma evolução das professoras-alunas, tanto no domínio do uso das TICs como na sua utilização em seu exercício profissional. Essa mudança de postura destes sujeitos analisados na pesquisa está claramente baseada na intersecção de duas diretrizes que só foi possível com o Curso PED/UFRGS: o domínio dos recursos tecnológicos por parte das professoras-alunas e a oportunidade de utilização destes instrumentos dentro de uma proposta pedagógica inovadora, caracterizada pela interação e pela problematização. Ao se tornarem agentes de seu próprio conhecimento, as professoras-alunas puderam iniciar um caminho de reflexão em busca da transposição didática deste aprendizado para sua prática pedagógica, tornando também seus alunos agentes de seu próprio processo de construção do conhecimento.

Tal situação prova que a simples utilização e domínio das TICs não garantem a transposição didática e que os Cursos de ensino a distancia devem estar preocupados não só com o uso da tecnologia, mas também com a modificação de sua proposta pedagógica. O uso das TICs no ensino prevê um modelo de aprendizagem diferente daquele tradicionalmente utilizado na sala de aula. Quando se está diante, ainda, de um público especialmente formado por professores, o comportamento com o uso de pedagogias inovadoras se torna mais premente, com vistas à simetria invertida já comentada.

De modo geral, esta é uma reflexão inicial, porém consistente, que poderá dar subsídios tanto a outras pesquisas quanto a estratégias utilizadas pelo PEAD/UFRGS, por trazer ao conhecimento os dados relativos aos efeitos dessa formação no cotidiano de suas professoras-alunas. Espera-se que, com esta reflexão acerca da apropriação tecnológica e do uso das TICs pelos professores-alunos do Curso PEAD/UFRGS em sua prática docente, se possa contribuir para o aprofundamento das questões relativas ao ensino a distância, à formação de professores e ao uso de tecnologias em sala de aula. Muitas questões ainda surgiram dessa reflexão inicial. Variáveis aqui intervenientes, como a disponibilidade e a forma de acesso dos professores aos LIs, poderão ser fruto de maior atenção em trabalhos futuros. Observações mais minuciosas ou com maior número de sujeitos também poderão contribuir para uma reflexão mais aprofundada do assunto.

\section{Referências bibliográficas}

BRASIL. Ministério da Educação. Conselho Nacional de Educação. Resolução n. ${ }^{\circ}$ $1 / 2002$, de 18 de fevereiro de 2002. Diretrizes curriculares nacionais para a formação de professores da educação. Brasília: Conselho Nacional de Educação/CP,

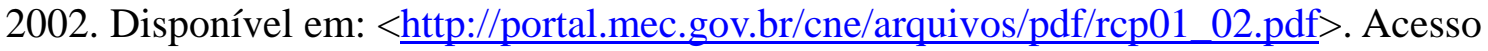
em: 01 fev. 2010. 
DOLLE, Jean Maria. Para compreender Jean Piaget. Uma iniciação à Psicologia Genética Piagetiana. Rio de Janeiro: Zahar Editores, 1974/1975.

KARMILOFF-SMITH, Annette. Beyond modularity: a developmental perspective on cognitive science. Cambridge, MA: Massachusetts Institute of Technology, Press/Bradford Books, 1995.

LEME, Maria Isabel da Silva. Reconciliando divergências: conhecimento implícito e explícito na aprendizagem. Revista Psicologia USP, vol.19, n. ${ }^{\circ}$ 2, São Paulo, jun. 2008. Disponível em: <http://pepsic.bvs-psi.org.br/scielo.php?script=sci_arttext\&pid=S1678-

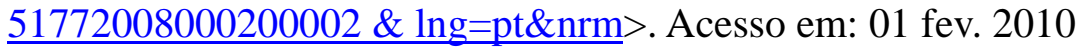

MORAES, Salete Campos de. In SCHOLZE, Lia e MORAES, Salete Campos de. Cadernos temáticos - multimeios e informática educativa. Para além da instrumentalização - a informática educativa como aplicação edificante do conhecimento. Secretaria Municipal de Educação. Prefeitura Municipal de Porto Alegre. Porto Alegre, 2002. p.19-22.

NEVADO, Rosane Aragón de et al. Guia do Aluno. Porto Alegre: FACED/UFRGS, 2006. Disponível em: <http://www.pead.faced.ufrgs.br/sites/publico/peadinformacoes/guia_do_professor.pdf>. Acesso em: 01 ago. 2008.

PIAGET, Jean. Biologia e conhecimento: ensaio sobre as relações entre as regulações orgânicas e os processos cognoscitivos. Petrópolis: Editora Vozes, 1973.

A equilibração das estruturas cognitivas. Problema central do desenvolvimento. Rio de Janeiro: Zahar Editores, 1976.

PRETTO, Nelson. Educação artesão impregnada de tecnologias. In: SIQUEIRA, Neiva Alves de; XAVIER, Adriana Gonçalves; MEDEIROS, Aimone Cristina da S. (Org.). Tecendo aprendizagens com a Rede Municipal de Ensino de Porto Alegre. Porto Alegre: SMED, 2006, p. 13-29. (Conversações Pedagógicas na Cidade que Aprende; v. 2)

PROINFO INTEGRADO, 2010. Disponível em:

http://portal.mec.gov.br/index.php?option=com_content\&view=article\&id=13156\&Item $\underline{\mathrm{id}=271}$ Acesso em 29 ago. 2010. 